Article

\title{
Integral Kinetic Model for Studying Quercetin Degradation and Oxidation as Affected by Cholesterol During Heating
}

\author{
John-Tung Chien, Da-Jung Hsu, Baskaran Stephen Inbaraj and Bing-Huei Chen * \\ Department of Food Science, Fu Jen University, Taipei 242, Taiwan; \\ E-Mails: 002604@mail.fju.edu.tw (J.T.C.); sinbaraj@yahoo.com (B.S.I.) \\ * Author to whom correspondence should be addressed; E-Mail: 002622@mail.fju.edu.tw; \\ Tel.: +886-2-2905-3626; Fax: +886-2-2902-1215.
}

Received: 7 July 2010; in revised form: 20 July 2010 / Accepted: 27 July 2010 /

Published: 29 July 2010

\begin{abstract}
The degradation and oxidation of quercetin, as affected by cholesterol during heating at $150{ }^{\circ} \mathrm{C}$, was kinetically studied using non-linear regression models. Both TLC and HPLC were used to monitor the changes of quercetin, cholesterol and cholesterol oxidation products (COPs) during heating. The formation of COPs, including triol, 7-keto, $7 \alpha-\mathrm{OH}$ and $7 \beta-\mathrm{OH}$, was completely inhibited during the initial 30 minute heating period in the presence of $0.02 \%$ quercetin, accompanied by reduction in cholesterol peroxidation and degradation. However, the quercetin degradation or oxidation proceeded fast, with the rate constants $\left(\mathrm{h}^{-1}\right)$ in the presence of nitrogen, oxygen and the combination of oxygen and cholesterol being $0.253,0.868$ and 7.17 , respectively. When cholesterol and quercetin were heated together, the rate constants $\left(\mathrm{h}^{-1}\right)$ of cholesterol peroxidation, epoxidation and degradation were $1.8 \times 10^{-4}, 0.016$ and 0.19 , respectively. The correlation coefficients $\left(\mathrm{r}^{2}\right)$ for all the oxidative and degradation reactions ranged from 0.82-0.99. The kinetic models developed in this study may be used to predict the degradation and oxidation of quercetin as affected by cholesterol during heating.
\end{abstract}

Keywords: quercetin; cholesterol oxidation; kinetic study 


\section{Introduction}

Flavonoids are ubiquitously distributed in food plants with approximately $90 \%$ occurring as glycosides in nature [1,2]. Among flavonoids, quercetin and its glycoside derivatives are the most abundant in plant vegetables [2,3], which have been reported to be effective in scavenging free radicals during lipid oxidation [4-6]. In addition, several studies have demonstrated that quercetin is more effective than $\alpha$-tocopherol and BHT in preventing cholesterol oxidation even at a low level [7-9].

To date, the kinetic study of the cholesterol oxidation pathway during heating has been well documented, showing the cholesterol oxidation is initiated by the second-order free radical chain reaction to form cholesterol hydroperoxides, followed by degradation to generate various cholesterol oxidation products (COPs), including 5,6 $\alpha-\mathrm{EP}, 5,6 \beta-\mathrm{EP}, 7 \alpha-\mathrm{OH}, 7 \beta-\mathrm{OH}$, 7-keto and triol [10-13]. In a recent study, $\mathrm{Xu}$ et al. [14] have shown the presence of four fatty acids, namely, stearic acid, oleic acid, linoleic acid and $\alpha$-linolenic acid, to promote oxidation of both cholesterol and $\beta$-sitosterol. As the consumption of COPs in excess may be detrimental to human health $[15,16]$, the inhibition of COPs formed during heating of cholesterol-rich foods is of great importance.

Up until now, there is a lack of data regarding the inhibition mechanism of cholesterol peroxidation as affected by quercetin. In a previous study dealing with development of a kinetic model for studying the effect of quercetin on cholesterol oxidation during heating, the reaction rate constants $\left(\mathrm{h}^{-1}\right)$ for epoxidation, dehydration and dehydrogenation of COPs, as well as free radical chain reaction and thermal degradation of cholesterol were reduced greatly after incorporation of quercetin [17]. However, the degradation or oxidation of quercetin remained unknown. In this report, our objective was to develop an integral mathematic model for studying the thermal degradation or oxidation of quercetin in the presence and absence of cholesterol. Additionally, the cholesterol peroxidation, epoxidation and degradation as affected by quercetin were determined. The result of this kinetic study may provide a further insight in elucidating the mechanism of quercetin degradation and oxidation as affected by cholesterol during heating.

\section{Results and Discussion}

\subsection{Changes of Quercetin during Heating with and without Cholesterol}

As an antioxidant, quercetin was reported to be more effective than $\alpha$-tocopherol in inhibiting lipid hydroperoxide formation even at a low level [7,8]. Of the various quercetin levels $(0.02,0.01,0.005$ and $0.002 \%$ of $100 \mathrm{mg}$ cholesterol), we found that with the exception of $0.02 \%$ quercetin, for all other levels the quercetin were drastically degraded during the initial 10 -min heating at $150{ }^{\circ} \mathrm{C}$ in the presence of cholesterol. Additionally, a $0.02 \%$ level of quercetin was efficient in inhibiting most COPs formation, with a significant residual amount of quercetin over a 30-min heating period (Figure 1). Thus, a level of $0.02 \%$ quercetin was selected in our study to elucidate the mechanism involved during heating of quercetin in the presence and absence of cholesterol. A heating temperature of $150{ }^{\circ} \mathrm{C}$ was chosen as cholesterol is prone to undergo autoxidation in liquid form when the temperature reaches its melting point of $148.5^{\circ} \mathrm{C}$ or higher [17]. Furthermore, thermal degradation of cholesterol has been reported to dominate over autoxidation at $200-300{ }^{\circ} \mathrm{C}$ [17]. It is also the temperature similar to that used for low-temperature frying of foods [17]. Thus, the heating temperature of $150{ }^{\circ} \mathrm{C}$ was selected in 
this study to reduce the loss of cholesterol due to thermal degradation and concomitantly accelerate the formation of COPs as well as to mimic the low-temperature frying conditions of foods.

Figures 1, 2 and 3 show the HPLC chromatograms of quercetin during heating at $150{ }^{\circ} \mathrm{C}$ in the presence of both oxygen and cholesterol, oxygen and nitrogen, respectively. With nitrogen, the amount of quercetin decreased gradually and a loss of 7.9, 17.2, 28.6 and 33.9\% was generated after $10 \mathrm{~min}$, 0.5, 1 and $2 \mathrm{~h}$ of heating, respectively (Figures 3 and 4). However, a greater loss of 20.4, 28.2, 64.8 and $82.4 \%$ of quercetin occurred when heated with oxygen for the same period (Figures 2 and 4). Apparently the quercetin degradation or oxidation exhibited a similar pattern when heated under nitrogen or oxygen, which is in accordance with a report by Makris and Rossiter [5,6]. In contrast, when heated with both cholesterol and oxygen, the level of quercetin drastically decreased to 10.9 and $5.9 \%$ after 10 and $30 \mathrm{~min}$ of heating, respectively (Figure 4). This is probably because of fast formation of cholesterol hydroperoxide through hydrogen abstraction at $\mathrm{C}-7$ of cholesterol during the initial heating period [10,12], which may in turn accelerate quercetin degradation at $150{ }^{\circ} \mathrm{C}$. As a result, the free radical involved in reactions of cholesterol oxidation and the quercetin degradation can be combined into a pathway as depicted in Figure 5. The major reaction pathways and rate constants for cholesterol peroxidation and quercetin degradation are shown in Tables 3 and 4. Comparatively, quercetin was degraded faster with cholesterol than without cholesterol, which should be caused by formation of free radicals at C-7 of cholesterol as indicated above. Additionally, quercetin may undergo oxidative degradation $\left(\mathrm{Q} \rightarrow \mathrm{Q}_{\mathrm{o}}\right)$ or non-oxidative degradation $\left(\mathrm{Q} \rightarrow \mathrm{Q}_{\mathrm{d}}\right)$ during heating at $150{ }^{\circ} \mathrm{C}$, with the rate constant $\left(\mathrm{h}^{-1}\right)$ being higher for the former than for the latter. The reaction pathways for peroxidation and epoxidation of cholesterol were the same as those described in a previous study [17], with the exception that some other COPs, including 7-OH, 7-keto, triol and cholestan-3 $\beta, 5 \alpha, 6$-one, were excluded for kinetic study as they were not formed in the presence of quercetin over a heating period of $30 \mathrm{~min}$.

Figure 1. HPLC chromatograms of quercetin during heating at $150{ }^{\circ} \mathrm{C}$ under combination of oxygen and cholesterol.

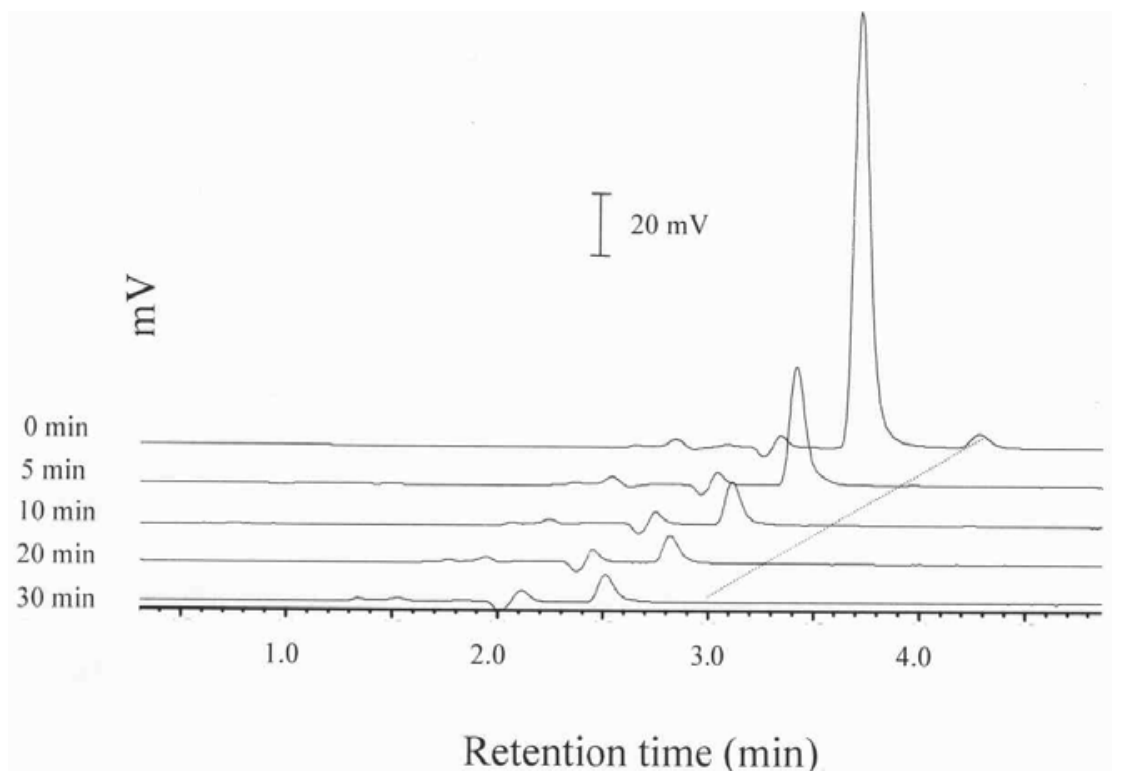


Figure 2. HPLC chromatograms of quercetin during heating at $150{ }^{\circ} \mathrm{C}$ under oxygen.

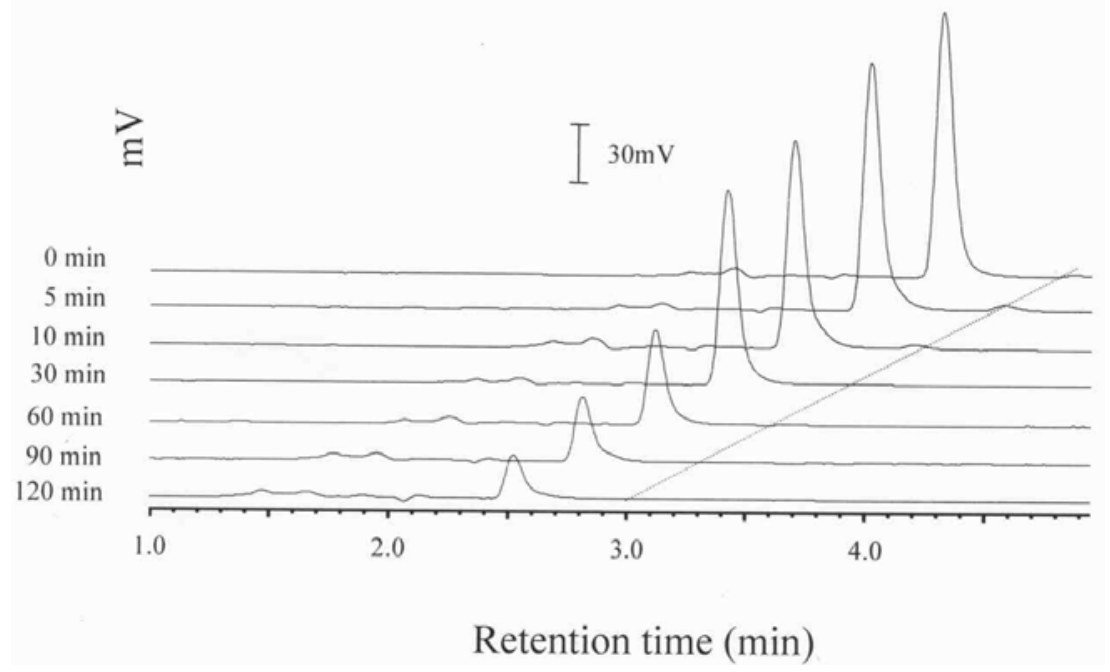

Figure 3. HPLC chromatograms of quercetin during heating at $150{ }^{\circ} \mathrm{C}$ under nitrogen.

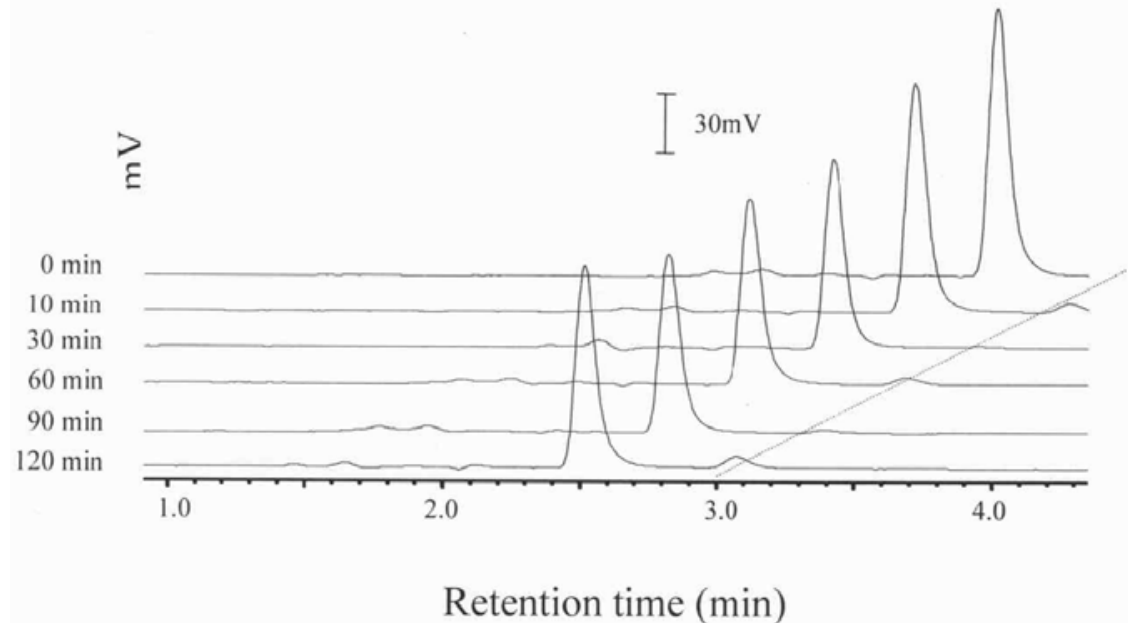

Figure 4. Changes of quercetin during heating at $150{ }^{\circ} \mathrm{C}$. Quercetin was heated under nitrogen $(\boldsymbol{\bullet})$, oxygen $(\bullet)$ or combination of oxygen and cholesterol $(\boldsymbol{\Delta})$; the best fitting line (-). A concentration of $200 \mu \mathrm{g} / \mathrm{g}$ quercetin was used.

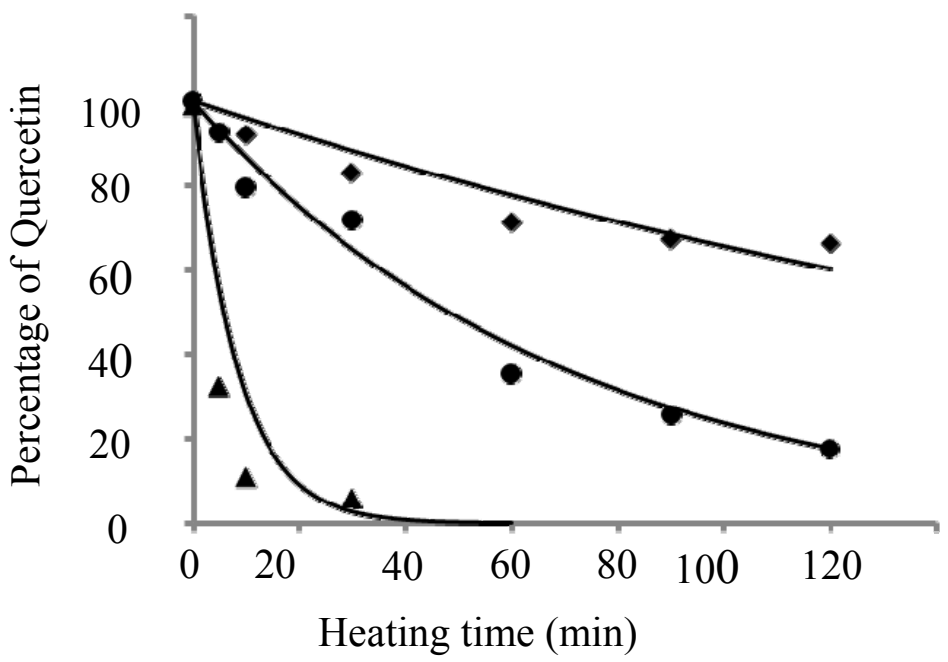


Figure 5. The possible pathways for quercetin degradation and oxidation as well as cholesterol peroxidation during heating at $150{ }^{\circ} \mathrm{C}$. Cholesterol (A); 7-hydroperoxycholesterol (A'); 5,6-epoxycholesterol (E); degraded products (D); quercetin $(\mathrm{Q})$; degraded plus oxidized product of quercetin $\left(\mathrm{Q}_{\mathrm{d}}, \mathrm{Q}_{\mathrm{o}}\right)$; quercetin free radical $\left(\mathrm{Q}^{*}\right)$. $\mathrm{k}_{1}$, $\mathrm{k}_{4}, \mathrm{k}_{5}, \mathrm{k}_{\mathrm{o}}, \mathrm{k}_{\mathrm{d}}$, and $\mathrm{k}_{\mathrm{f}}$ are the corresponding rate constants.

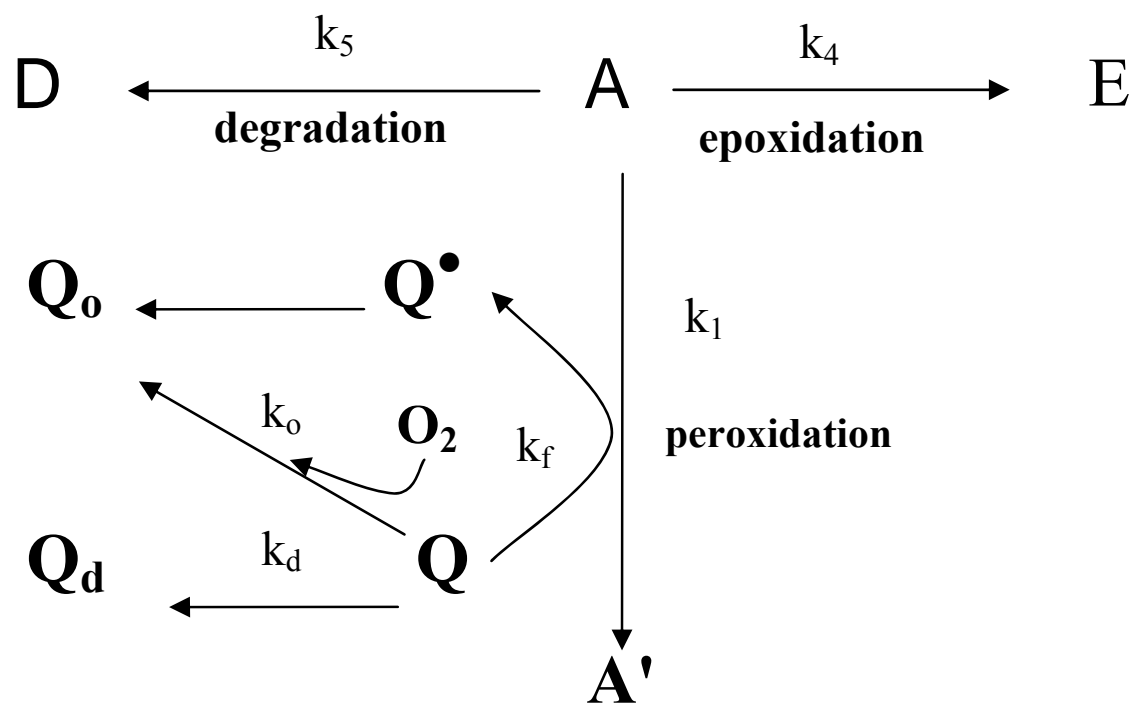

Figure 6. HPLC chromatogram of the acetone extract obtained from TLC after heating cholesterol with quercetin for $30 \mathrm{~min}$.

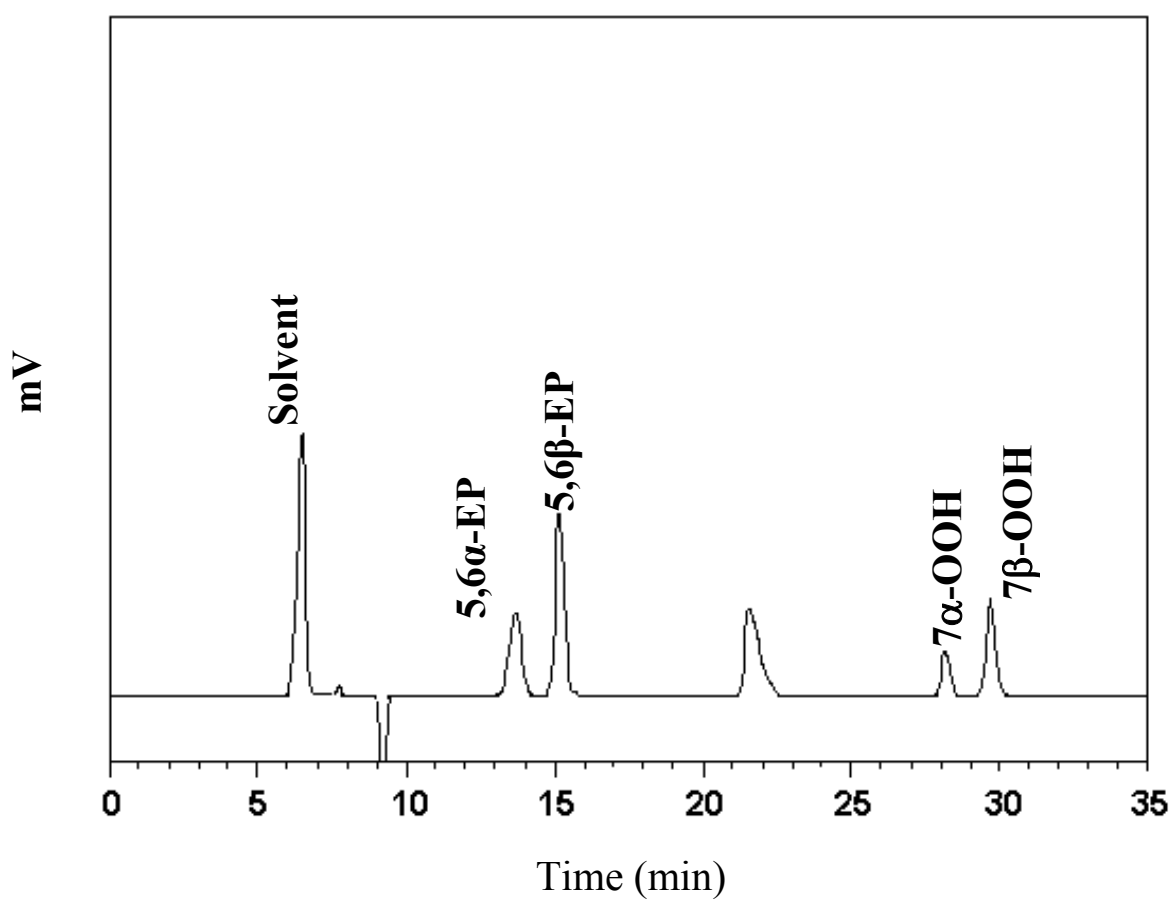




\subsection{Peroxidation and Epoxidation of Cholesterol during Heating}

Due to absence of cholesterol hydroperoxide standards, both $7 \alpha-\mathrm{OOH}$ and $7 \beta-\mathrm{OOH}$ should be identified and quantified with care. According to Smith and Hill [18], both $7 \alpha-\mathrm{OOH}$ and $7 \beta-\mathrm{OOH}$ could turn red after spraying $N, N$-dimethyl-p-phenylenediamine dihydrochloride onto a TLC plate. Both $7 \alpha-\mathrm{OOH}$ and $7 \beta-\mathrm{OOH}$ were further subjected to HPLC analysis for identification. Figure 6 shows the HPLC chromatogram of the acetone extract of the red spots collected from TLC after heating cholesterol with quercetin for $30 \mathrm{~min}$. A total of 5 peaks were present, in which 5,6 $\alpha$-EP, $5,6 \beta-\mathrm{EP}, 7 \alpha-\mathrm{OOH}$ and $7 \beta-\mathrm{OOH}$ were identified. Both $7 \alpha-\mathrm{OOH}$ and $7 \beta-\mathrm{OOH}$ were tentatively identified based on the retention behavior as described by Chien et al. [17].

Figure 7. The amounts of $7-\mathrm{OOH}(7 \alpha-\mathrm{OOH}$ plus $7 \beta-\mathrm{OOH})$ formed during heating of cholesterol with and without quercetin at $150{ }^{\circ} \mathrm{C}$. Means of experimental data of cholesterol in the absence of quercetin ( $\bullet$ ), and cholesterol in the presence of quercetin $(\bullet)$; the best fitting line (-).

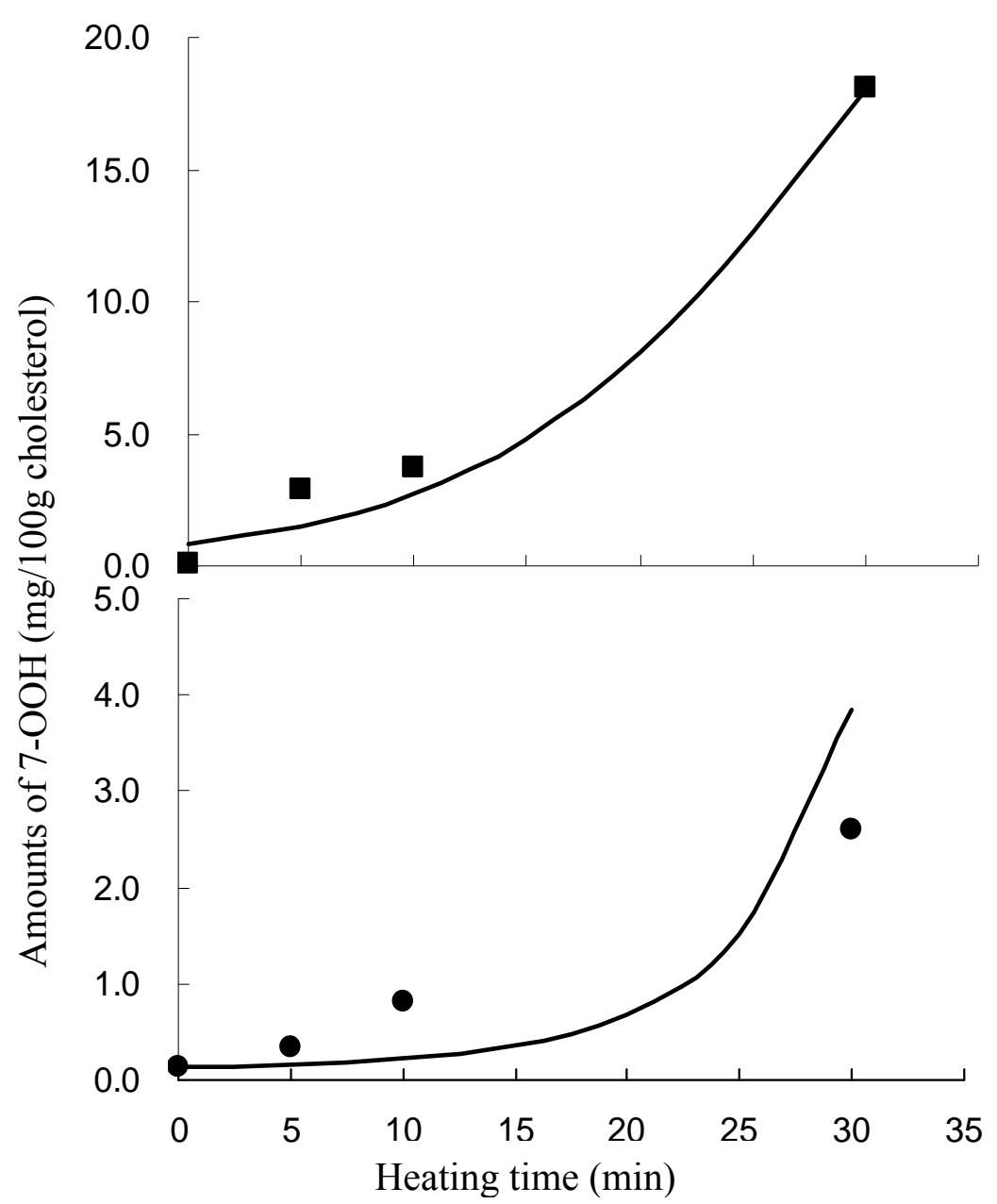

A total of eight major COPs, namely, 5,6 $\alpha$-EP, 5,6 $\beta$-EP, 7-keto, $7 \alpha-\mathrm{OH}, 7 \beta-\mathrm{OH}, 7 \alpha-\mathrm{OOH}$, $7 \beta-\mathrm{OOH}$, and triol, were adequately resolved within $30 \mathrm{~min}$ by using the HPLC condition shown in the method section (Figure not shown). Interestingly, with quercetin, $7 \alpha-\mathrm{OH}, 7 \beta-\mathrm{OH}, 7-\mathrm{keto}$ and triol were 
undetected over a 30-min heating period (Figure 6). Conversely, without quercetin, all the eight COPs (5,6 $\alpha$-EP, $5,6 \beta-\mathrm{EP}, 7-\mathrm{keto}, 7 \alpha-\mathrm{OH}, 7 \beta-\mathrm{OH}, 7 \alpha-\mathrm{OOH}$, and $7 \beta-\mathrm{OOH}$ and triol) were formed gradually during heating, with the level of $7-\mathrm{OOH}(7 \alpha-\mathrm{OOH}$ plus $7 \beta-\mathrm{OOH})$ being $0.82 \mathrm{mg}$ (based on $100 \mathrm{~g}$ cholesterol) in the beginning, raised to $3.7 \mathrm{mg}$ in $10 \mathrm{~min}$ and $18 \mathrm{mg}$ in $30 \mathrm{~min}$, whereas in the presence of quercetin, the initial level of 7-OOH was $0.13 \mathrm{mg}$, rose to $0.82 \mathrm{mg}$ in $10 \mathrm{~min}$ and $2.6 \mathrm{mg}$ in $30 \mathrm{~min}$

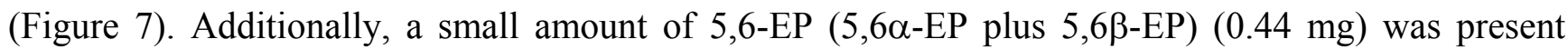
prior to heating, rose to $3.2 \mathrm{mg}$ in $10 \mathrm{~min}$ and $17.7 \mathrm{mg}$ in $30 \mathrm{~min}$. However, with quercetin treatment, a level of $0.46 \mathrm{mg} 5,6$-EP (based on $100 \mathrm{~g}$ cholesterol) was formed initially, followed by an increment to $1.00 \mathrm{mg}$ in $10 \mathrm{~min}$ and $2.83 \mathrm{mg}$ in $30 \mathrm{~min}$. This outcome is different from that reported by Chien et al. [17], as the inhibition of 7-OH ( $7 \alpha-\mathrm{OH}$ plus $7 \beta-\mathrm{OH}), 7$-keto and triol were not possible in the presence of $0.002 \%$ quercetin. Obviously a higher level of $0.02 \%$ quercetin employed in the present experiment should account for this effect.

Table 1 shows the total COPs formed during heating with or without quercetin at $150{ }^{\circ} \mathrm{C}$. The amount of COPs generated during heating followed a time-dependent response for both treatments, with a lesser content for the treatment with quercetin. For instance, the amount of COPs produced with quercetin was 11.6-fold lower than that without quercetin after 30-min heating, demonstrating the potential of quercetin to be a powerful antioxidant.

Table 1. Inhibitory effect of quercetin on total COPs formed during heating at $150{ }^{\circ} \mathrm{C}$.

\begin{tabular}{ccc}
\hline $\begin{array}{c}\text { Heating time } \\
\text { (min) }\end{array}$ & COPs (\%) $^{\mathrm{a}}$ \\
\cline { 2 - 3 } & Control $^{\mathrm{b}}$ & Quercetin $^{\mathrm{b}}$ \\
\hline 0 & $0.08 \pm 0.00^{\mathrm{A}, \mathrm{a}}$ & $0.07 \pm 0.00^{\mathrm{A}, \mathrm{b}}$ \\
5 & $0.18 \pm 0.01^{\mathrm{A}, \mathrm{a}}$ & $0.09 \pm 0.00^{\mathrm{A}, \mathrm{b}}$ \\
10 & $0.94 \pm 0.01^{\mathrm{B}, \mathrm{a}}$ & $0.16 \pm 0.01^{\mathrm{A}, \mathrm{b}}$ \\
60 & $5.94 \pm 0.05^{\mathrm{C}, \mathrm{a}}$ & $0.51 \pm 0.00^{\mathrm{B}, \mathrm{b}}$ \\
90 & $15.4 \pm 0.3^{\mathrm{D}, \mathrm{a}}$ & $2.05 \pm 0.03^{\mathrm{C}, \mathrm{b}}$ \\
120 & $30.9 \pm 0.5^{\mathrm{E,a}}$ & $7.77 \pm 0.06^{\mathrm{D}, \mathrm{b}}$ \\
\hline
\end{tabular}

a Values are expressed as percentage relative to cholesterol content at 0 min heating time; mean \pm standard deviation of triplicate determinations.

b Symbols bearing the letters A-E in the same column or a-b in the same row are significantly different $(\mathrm{p}<0.05)$;

c Not detected.

Table 2 shows the percentage changes of residual cholesterol during thermal degradation at $150{ }^{\circ} \mathrm{C}$. As it is difficult to estimate the concentration change of thermal degraded data $\left(\mathrm{C}_{\mathrm{T}}\right)$, the data in Table 2 were recalculated by combining the amounts of COPs $\left(\mathrm{C}_{\mathrm{O}}\right)$ and residual cholesterol $\left(\mathrm{C}_{\mathrm{R}}\right)$ at each interval, i.e., total cholesterol $=\mathrm{C}_{\mathrm{T}}+\mathrm{C}_{\mathrm{O}}+\mathrm{C}_{\mathrm{R}}$ or total cholesterol $-\mathrm{C}_{\mathrm{T}}=\mathrm{C}_{\mathrm{O}}+\mathrm{C}_{\mathrm{R}}=$ actual residual cholesterol due to thermal degradation, so that the overall thermal degradation rate constant could be estimated. The residual concentrations of cholesterol were significantly different between treatments with and without quercetin for the same heating time. Nevertheless, a slight difference in cholesterol loss did occur after extensive heating for 60 and $90 \mathrm{~min}$, as evidenced by a decline of 35.8 and 33.6\% 
without quercetin respectively, in contrast to 19.5 and $22.9 \%$ with quercetin. This outcome implied that the thermal degradation of cholesterol proceeded fast in the beginning and a plateau was reached after prolonged heating. By comparing the data in Tables 1 and 2, a reversed trend was shown to occur for oxidative degradation, i.e., it proceeded slower in the initial period and faster after extensive heating.

Table 2. Percentage changes of residual cholesterol due to thermal degradation at $150{ }^{\circ} \mathrm{C}$.

\begin{tabular}{ccc}
\hline $\begin{array}{c}\text { Heating time } \\
(\mathbf{m i n})\end{array}$ & \multicolumn{2}{c}{ Cholesterol (\%) $^{\mathbf{a}}$} \\
\cline { 2 - 3 } Control $^{\mathbf{b}}$ & Quercetin $^{\mathbf{b}}$ \\
\hline 0 & $97.9 \pm 0.6^{\mathrm{A}, \mathrm{a}}$ & $96.9 \pm 0.3^{\mathrm{A}, \mathrm{a}}$ \\
5 & $93.2 \pm 1.05^{\mathrm{B}, \mathrm{a}}$ & $95.7 \pm 0.2^{\mathrm{A}, \mathrm{b}}$ \\
30 & $87.5 \pm 0.4^{\mathrm{C}, \mathrm{a}}$ & $94.1 \pm 0.1^{\mathrm{A}, \mathrm{b}}$ \\
60 & $69.0 \pm 1.0^{\mathrm{D}, \mathrm{a}}$ & $86.4 \pm 0.1^{\mathrm{B}, \mathrm{b}}$ \\
90 & $64.2 \pm 0.9^{\mathrm{E}, \mathrm{a}}$ & $80.5 \pm 0.3^{\mathrm{C}, \mathrm{b}}$ \\
120 & $66.4 \pm 0.7^{\mathrm{E}, \mathrm{a}}$ & $77.1 \pm 0.5^{\mathrm{D}, \mathrm{b}}$ \\
\hline
\end{tabular}

a Values are expressed as percentage relative to cholesterol content at 0 min heating time; mean \pm standard deviation of triplicate determinations.

b Symbols bearing different letters of A-E in the same column or a-b in the same row are significantly different $(\mathrm{p}<0.05)$;

c Not detected.

\subsection{Kinetic Studies of Quercetin Degradation and Oxidation as well as Cholesterol Hydroperoxide}

\section{Formation}

The free radical chain reaction of cholesterol oxidation can be inhibited in the presence of quercetin, a free radical scavenger $[5,6,19,20]$. The initial oxidation and thermal degradation pathways of cholesterol as well as the thermal degradation and oxidation pathways of quercetin are shown in Figure 5. According to the kinetic studies of antioxidants by Pryor et al. [19] and Foti et al. [21], with quercetin the hydroperoxide formation rate can be expressed as follows:

$$
\frac{\mathrm{d}[\mathrm{COOH}]}{\mathrm{d} t}=\frac{k[R H] R_{i}}{n k^{\prime}[Q]}
$$

where [Q]: percentage concentration of quercetin

$[\mathrm{COOH}]:$ the concentration of hydroperoxide

$[\mathrm{RH}]$ : the concentration of target compound to be oxidized

$\mathrm{R}_{\mathrm{i}}$ : the initial reaction rate

$\mathrm{k}, \mathrm{k}^{\prime}$ : the reaction rate constant

$\mathrm{n}$ : number of free radicals scavenged per quercetin molecule

If all the thermal degradation, oxidation and free radical chain reactions for quercetin followed a first-order, the depletion rate of quercetin can be written by setting $n . k^{\prime}=k_{f}$ as follows: 


$$
-\frac{\mathrm{d}[\mathrm{Q}]}{\mathrm{dt}}=\mathrm{k}_{\mathrm{d}}[\mathrm{Q}]+\mathrm{k}_{\mathrm{O}}[\mathrm{Q}]+\mathrm{k}_{\mathrm{f}}[\mathrm{Q}]=\left(\mathrm{k}_{\mathrm{d}}+\mathrm{k}_{\mathrm{O}}+\mathrm{k}_{\mathrm{f}}\right)[\mathrm{Q}]=k_{i}[\mathrm{Q}]
$$

where $\mathrm{k}_{\mathrm{d}}, \mathrm{k}_{\mathrm{o}}, \mathrm{k}_{\mathrm{f}}$, and $\mathrm{k}_{\mathrm{i}}$ : the reaction rate constants $\left(\mathrm{h}^{-1}\right)$ for thermal degradation, oxidation, free radical scavenging and the overall degradation, respectively.

According to the studies by Ozilgen and Ozilgen [22] and Chien et al. [12], the rate equation for forward formation of $7-\mathrm{OOH}$ from cholesterol through free radical chain reaction $\left(A \rightarrow A^{\prime}\right)$ is as follows:

$$
\frac{\mathrm{d}\left[\mathrm{A}^{\prime}\right]}{\mathrm{dt}}=\mathrm{k}_{1}\left(1-\frac{\left[\mathrm{A}^{\prime}\right]}{\left[\mathrm{A}^{\prime}\right]_{\max }}\right)\left[\mathrm{A}^{\prime}\right]
$$

where $\left[\mathrm{A}^{\prime}\right]$ : percentage concentration of $7-\mathrm{OOH}$

$\left[\mathrm{A}^{\prime}\right]_{\max }$ : the maximum attainable concentration of 7-OOH prior to degradation

$\mathrm{k}_{1}$ : the reaction rate constant and $\mathrm{t}$ : time.

Combining Equations (1)-(3), the Equation (4) for 7-OOH formation could be obtained by setting $[\mathrm{COOH}]=\left[\mathrm{A}^{\prime}\right]$ as follows:

$$
\frac{\mathrm{d}\left[\mathrm{A}^{\prime}\right]}{\mathrm{dt}}=\frac{\mathrm{k}_{1}\left[\mathrm{~A}^{\prime}\right]}{\mathrm{k}_{\mathrm{f}}[\mathrm{Q}]}\left[1-\frac{\left[\mathrm{A}^{\prime}\right]}{\left[\mathrm{A}^{\prime}\right]_{\max }}\right]
$$

For the second-order formation of 5,6-EP from cholesterol, the concentrations of both cholesterol and $7-\mathrm{OOH}$ should be considered [12,23]. Thus, if we also consider the involvement of free radical scavenging effect of quercetin in epoxidation, the rate equations for 5,6-EP formation should be expressed as follows:

$$
\frac{\mathrm{d}[\mathrm{E}]}{\mathrm{dt}}=\frac{\mathrm{k}_{4}[\mathrm{~A}]\left[\mathrm{A}^{\prime}\right]}{\mathrm{k}_{\mathrm{f}}[\mathrm{Q}]}
$$

Furthermore, it was reported that thermal degradation of cholesterol follows first-order reaction $[12,13]$ and the corresponding equation can be given as in Equation (1) in a previous study [17]. The integral form is as follows:

$$
[A]=\left[A_{0}\right] e^{-k_{5} t}
$$

The following Equation (7) can be obtained by integrating of Equation (2).

$$
[\mathrm{Q}]=[\mathrm{Q}]_{0} \mathrm{e}^{-\mathrm{k}_{\mathrm{i}} \mathrm{t}}
$$

Likewise, Equations (7-1) and (7-2) were used for estimating quercetin degradation under nitrogen and oxygen, respectively. Both equations can be obtained by integration of the first-order rate equation of thermal degradation and oxidative degradation of quercetin as follows:

$$
\begin{aligned}
& {[Q]=[Q]_{0} e^{-k_{d} t}} \\
& {[Q]=[Q]_{0} e^{-\left(k_{d}+k_{O}\right) t}}
\end{aligned}
$$


Integration after substituting Equations (7) into Equation (4) gave Equation (8) as follows:

$$
\left[\mathrm{A}^{\prime}\right]=\frac{\left[\mathrm{A}^{\prime}\right]_{\text {max }}}{1-\left(1-\frac{\left[\mathrm{A}^{\prime}\right] \max }{\left[\mathrm{A}^{\prime}\right]_{0}}\right) \omega}
$$

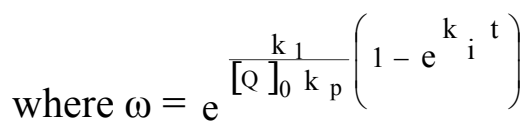

$\mathrm{k}_{\mathrm{P}}=\mathrm{k}_{\mathrm{i}} \times \mathrm{k}_{\mathrm{f}}$

$[\mathrm{A}]_{0},\left[\mathrm{~A}^{\prime}\right]_{0},[\mathrm{E}]_{0},[\mathrm{Q}]_{0}$ : concentration of cholesterol, 7-OOH, 5,6-EP and quercetin at 0 -min heating

Integration after substitution of Equations (6), (7) and (8) into Equation (5), the following Equation (9) can be obtained.

$$
[\mathrm{E}]=[\mathrm{E}]_{0}+\frac{\mathrm{k}_{4}[\mathrm{~A}]_{0}\left[\mathrm{~A}^{\prime}\right]_{\max }}{\mathrm{k}_{\mathrm{p}}[\mathrm{Q}]_{0}} \int_{0}^{\mathrm{t}} \frac{\mathrm{e}^{\left(k_{i}-k_{5}\right) \mathrm{t}}}{1-\left(1-\frac{\left[\mathrm{A}^{\prime}\right] \max }{\left[\mathrm{A}^{\prime}\right]_{0}}\right) \omega} \mathrm{dt}
$$

Among the above equations, Equations (6), (7) and (8) are in the forms of exact integration. As the exact integrations for Equation (9) are not possible, we can only get a better approximation to the integral term in equation by using a quadratic polynomial of Taylor's series as follows:

$$
\begin{aligned}
{[\mathrm{E}] } & =[\mathrm{E}]_{0}+\frac{\mathrm{k}_{4}[\mathrm{~A}]_{0}\left[\mathrm{~A}^{\prime}\right]_{0}}{\mathrm{k}_{\mathrm{p}}[\mathrm{Q}]_{0}\left(\mathrm{k}_{\mathrm{i}}-\mathrm{k}_{5}\right)}\left[\left(1+\mathrm{m}_{3}\left(1-\mathrm{m}_{2}\right) \mathrm{t}+\mathrm{m}_{4} \mathrm{t}^{2}\right) \mathrm{e}^{\left(k_{i}-k_{5}\right) \mathrm{t}}-\left(\frac{\mathrm{m}_{3}\left(1-\mathrm{m}_{2}\right)+2 \mathrm{~m}_{4} \mathrm{t}}{\mathrm{k}_{\mathrm{i}}-\mathrm{k}_{5}}\right) \mathrm{e}^{\left(k_{i}-k_{5}\right) \mathrm{t}}\right. \\
& \left.+\frac{2 \mathrm{~m}_{4}}{\left(\mathrm{k}_{\mathrm{i}}-\mathrm{k}_{5}\right)^{2}} \mathrm{e}^{\left(k_{i}-k_{5}\right) \mathrm{t}}-1+\left(\frac{\mathrm{m}_{3}\left(1-\mathrm{m}_{2}\right)}{\mathrm{k}_{\mathrm{i}}-\mathrm{k}_{5}}\right)-\frac{2 \mathrm{~m}_{4}}{\left(\mathrm{k}_{\mathrm{i}}-\mathrm{k}_{5}\right)^{2}}\right]
\end{aligned}
$$

where $\left.\mathrm{m}_{2}=\left[\mathrm{A}^{\prime}\right]_{0} / \mathrm{A}^{\prime}\right]_{\max }$;

$$
\begin{aligned}
& \mathrm{m}_{3}=\mathrm{k}_{1} / \mathrm{k}_{\mathrm{f}}[\mathrm{Q}]_{0} ; \\
& \mathrm{m}_{4}=\mathrm{m}_{3}\left(2 \mathrm{~m}_{3} \mathrm{~m}_{2}^{2}-\mathrm{m}_{2} \mathrm{k}_{\mathrm{i}}-3 \mathrm{~m}_{2} \mathrm{~m}_{3}+\mathrm{k}_{\mathrm{i}}+\mathrm{m}_{3}\right) .
\end{aligned}
$$

The experimental data were thus analyzed in sequence and fitted best to the corresponding nonlinear regression model. The residual percentage of quercetin in Figure 4 was used for computing the reaction rate constants $\left(\mathrm{h}^{-1}\right)$ for thermal degradation $\left(\mathrm{k}_{\mathrm{d}}\right)$, oxidation $\left(\mathrm{k}_{\mathrm{o}}\right)$ and the overall degradation $\left(\mathrm{k}_{\mathrm{i}}\right)$. The Equations (7-1), (7-2) and (7) implied that for a first-order reaction, the natural logarithm of the residual quercetin percentage is a linear function of time and thus, $\mathrm{k}_{\mathrm{d}}, \mathrm{k}_{\mathrm{o}}$, and $\mathrm{k}_{\mathrm{i}}$ in Equations (7-1), (7-2) and (7) can be estimated using a linear regression model [24]. The results are shown in Table 3, with $\mathrm{K}_{\mathrm{d}}$ being $0.253 \mathrm{~h}^{-1}$ and correlation coefficients $\left(\mathrm{r}^{2}\right) 0.94$, which was lower than that for oxidative degradation of quercetin $\left(\mathrm{k}_{\mathrm{O}}\left(\mathrm{h}^{-1}\right)=0.615=0.868-0.253\right)$. Although the correct value of $\mathrm{k}_{\mathrm{f}}$ for quercetin degradation in the free radical chain reaction should be evaluated from Equation (8), the $\mathrm{k}_{\mathrm{f}}$ $\left(\mathrm{h}^{-1}\right)$ values from Equations (7-2) and (7) $\left(6.302 \mathrm{~h}^{-1}\right.$ or $\left.7.17-0.868 \mathrm{~h}^{-1}\right)$ can still be used for subsequent comparison, and was approximately 24.9 and 10.2-folds higher than $\mathrm{k}_{\mathrm{d}}$ or $\mathrm{k}_{\mathrm{O}}$, respectively.

The data in Table 2 were used for computing $\mathrm{k}_{5}$ in Equation (6) by using a linear regression model [24], with $\mathrm{K}_{5}\left(\mathrm{~h}^{-1}\right)$ being $0.19 \pm 0.01\left(\mathrm{r}^{2}=0.99\right)$, which was lower than the treatment without quercetin 
$(0.94 \pm 0.03)$ by 4.9 -fold (Table 4$)$. The rate constants in Equations (8) and (10) were estimated by using the least squares method with a nonlinear Marquardt iterative method until the convergences of best-fitted parameters were met. Table 4 shows the rate constants of the reaction pathways of cholesterol peroxidation and epoxidation as well as free radical chain reaction and degradation of quercetin over a 30-min heating period. With quercetin, the $r^{2}$ of all the reactions were higher than 0.82 , especially for the free radical chain reaction of quercetin, as a high $\mathrm{r}^{2}(0.94)$ was found after a non-linear estimation from Equation (8) with a $\mathrm{k}_{\mathrm{f}}\left(\mathrm{h}^{-1}\right)$ of 3.28. This value was close to that estimated from Equation (7), i.e., $6.302=7.17-0.868$ in Table 3 by a difference of 1.9-fold. Though we do not have a plausible explanation for the difference in $\mathrm{k}_{\mathrm{f}}$ value, it may be possibly due to the low amount of COPs formed over a 30-min heating period (Table 1), which made it more difficult to estimate the $\mathrm{k}_{\mathrm{f}}$ value from Equation (8). By combining all the results shown above, it is apparent that all the reactions involved for quercetin during heating, including thermal degradation, oxidative degradation and free radical chain reaction, fit well the first-order model. In addition, the formation of 7-OOH, the initial oxidation product generated from peroxidation of cholesterol, was further plotted based on the corresponding rate equation, i.e., Equation (8) (Figure 7) and the rate constants are listed in Table 4. Both curves fitted well with the data points with or without quercetin. All these findings suggested that the Equation (8) could successfully estimate the degradation of cholesterol and quercetin over a 30 min heating period.

Table 3. Oxidation and degradation rate constants of quercetin during heating at $150{ }^{\circ} \mathrm{C}$.

\begin{tabular}{|c|c|c|c|c|}
\hline Treatment & & Rate equations $^{\text {a }}$ & $k\left(h^{-1}\right)$ & $\mathbf{r}^{2}$ \\
\hline Nitrogen & & $\mathrm{kd} \longrightarrow \mathrm{Q}_{\mathrm{d}}$ & $0.253 \pm 0.027$ & 0.94 \\
\hline Oxygen & Q & $\stackrel{\mathrm{kd}+\mathrm{ko}}{\longrightarrow} \mathrm{Q}_{\mathrm{d}}+\mathrm{Q}_{\mathrm{o}}$ & $0.868 \pm 0.019$ & 0.99 \\
\hline Oxygen and Cholesterol & Q & $\stackrel{\mathrm{kd}+\mathrm{ko}+\mathrm{kf}}{\longrightarrow} \mathrm{Q}_{\mathrm{d}}+\mathrm{Q}_{\mathrm{o}}+\mathrm{Q}^{\bullet}$ & $7.17 \pm 0.67$ & 0.91 \\
\hline
\end{tabular}

Table 4. Oxidation and degradation rate constants of cholesterol during heating at $150{ }^{\circ} \mathrm{C}$.

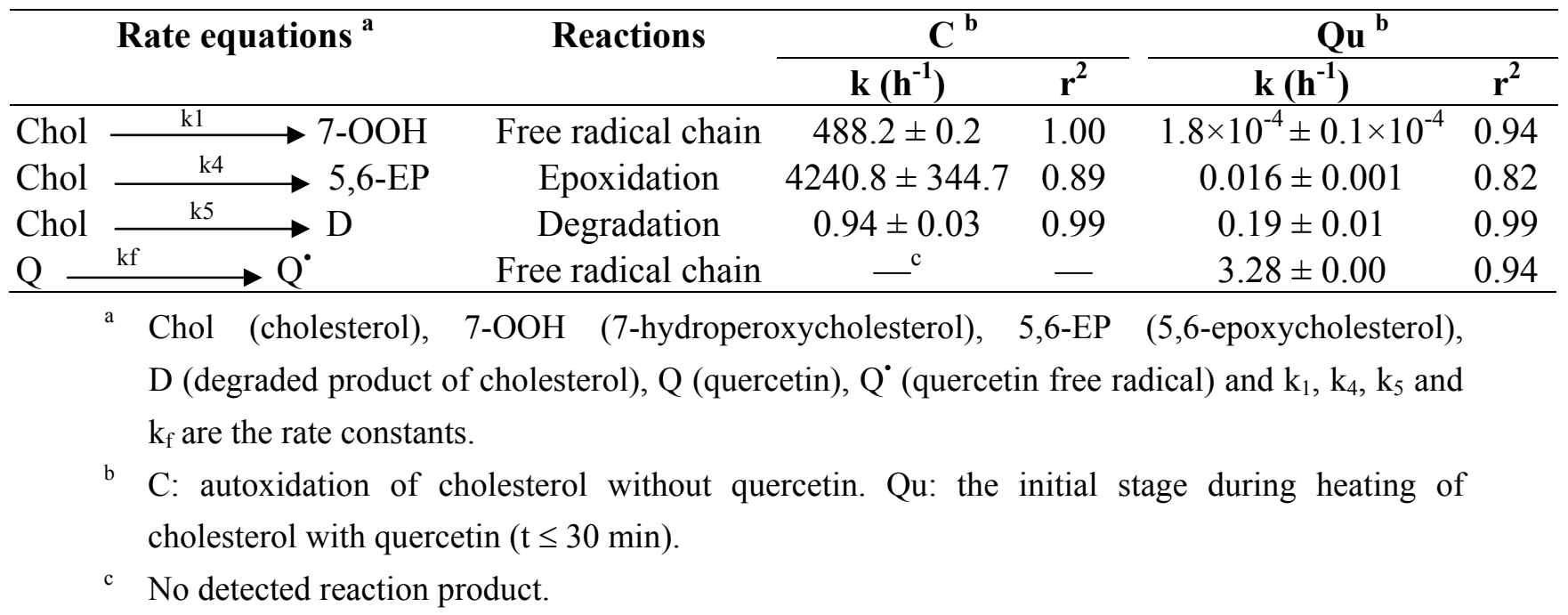


For cholesterol oxidation in the presence of quercetin, the $\mathrm{r}^{2}$ of peroxidation and epoxidation were 0.94 and 0.82 , respectively, whereas the free radical chain reaction of quercetin was 0.94 (Table 4). It may be postulated that both formation of 7-OOH and 5,6-epoxide during heating of cholesterol with quercetin fit the second-order, but the free radical chain reaction of quercetin fits the first-order.

It was also observed that the $\mathrm{k}_{1}\left(\mathrm{~h}^{-1}\right)$ dropped sharply from 488.2 for the treatment without quercetin to $1.8 \times 10^{-4}$ for the treatment with quercetin, implying the incorporation of $0.02 \%$ quercetin to be effective in inhibiting free radical formation. Similarly, a substantial decline in $\mathrm{k}_{4}$ by $2.7 \times 10^{5}$-fold after quercetin treatment was shown for epoxidation, which may be accounted for by a pronounced inhibition of 7-OOH formation during heating with quercetin. By comparison, the rate constants $\left(\mathrm{h}^{-1}\right)$ of the major reaction pathways of cholesterol oxidation in Table 4 followed the order: $\mathrm{k}_{5}>\mathrm{k}_{4}>\mathrm{k}_{1}$ for the quercetin treatment, and $\mathrm{k}_{4}>\mathrm{k}_{1}>\mathrm{k}_{5}$ for the treatment without quercetin.

\section{Experimental Section}

\subsection{Materials}

Several COPs standards, including 7 $\beta$-hydroxycholesterol $(7 \beta-\mathrm{OH}), 7 \alpha$-hydroxycholesterol

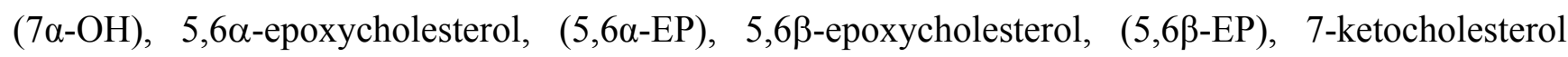
(7-keto) and $5 \alpha$-cholestane-3 $\beta, 5,6 \beta$-triol (triol) were purchased from Sigma (St. Louis, MO, USA) and Steraloids Inc. (Wilton, NH, USA). Standards of cholesterol, quercetin and lauryl alcohol were also from Sigma and were used without further purification. The HPLC-grade solvents such as n-hexane, ethanol, methanol and isopropanol were from Mallinckrodt Co. (Paris, KY, USA). The analytical grade solvent 1,2-dichloroethane was from Riedel-de Haën Co. (Barcelona, Spain). Paraffin oil, acetonitrile, phosphoric acid and potassium dihydrogen phosphate were from Merck (Darmstadt, Germany). The $\mathrm{NH}_{2}$ cartridges were from Unichrom Scientific (Taipei, Taiwan). The Strata C18-E solid phase extraction cartridges $(500 \mathrm{mg} / 3 \mathrm{~mL}, 55 \mu \mathrm{m}, 70 \AA$ ) were from Phenomenex Co. (Torrance, CA, USA).

\subsection{Instrumentation}

The HPLC instrument was composed of a Jasco PU980 pump (Jasco Co., Tokyo, Japan), an UV-VIS detector, a Jasco 830 refractive index detector and an Agilent 1100 series G1316A column temperature controller (Palo Alto, CA). A Borwin software system was used to process data. A Vydac 201TP54 C18 column $(250 \times 4.6 \mathrm{~mm}$ i.d., 5- $\mu \mathrm{m}$ particle size; Vydac Inc., Hesperia, CA, USA) was used to separate and quantify quercetin in heated samples. Two Merck Lichrospher $100 \mathrm{CN}$ columns $(244 \times 2.4 \mathrm{~mm}$ i.d.) with both containing 5 - $\mu \mathrm{m}$ packing material were used to separate and quantify cholesterol as well as COPs in heated samples. The Sorvall RC5C high-speed centrifuge was from Du Pont (Wilmington, DL).

\subsection{Heating of Quercetin with or without Cholesterol}

A mixture containing $0.6-\mathrm{mL}$ of lauryl alcohol and 2.4-mL of paraffin oil was poured into a $100-\mathrm{mL}$ round-bottom flask, followed by adding $600 \mathrm{mg}$ of cholesterol standard and $0.12 \mathrm{mg}(0.02 \%$ of cholesterol) of quercetin dissolved in 2-mL of ethanol. Lauryl alcohol was used as a solvent to dissolve 
the mixture of cholesterol and quercetin, as well as induce triol formation in an aqueous system through alcoholysis of the epoxy-containing COPs [17]. The flask was soaked in a paraffin-oil bath, which was preheated for $5 \mathrm{~min}$ with nitrogen gas flushing into the flask at the same time until the internal temperature reached $150 \pm 1{ }^{\circ} \mathrm{C}$. Then, oxygen was pumped into the flask during heating for 0 , 5, 10, 20 and $30 \mathrm{~min}$. After heating, the flask was inserted into dry ice to terminate the reaction and then each sample was analyzed by HPLC. For the other two treatments, the same procedure as described for heating of quercetin with cholesterol was used with the exception that $1.0 \mathrm{mg}$ of quercetin was heated alone and the heating times were changed to 0, 5, 10, 30, 60, 90 and $120 \mathrm{~min}$, with nitrogen or oxygen being pumped-in separately. For each heating treatment, triplicate experiments were carried out and the data were analyzed by a non-linear regression method [24].

\subsection{Extraction and Purification of Cholesterol and COPs}

A method based on Nourooz-Zadeh [25] was modified for extraction and purification of COPs from the samples containing quercetin and cholesterol. Each heated sample was mixed with $20-\mathrm{mL}$ of hexane-isopropanol $(3: 2, \mathrm{v} / \mathrm{v})$, and the solution was flushed with nitrogen gas and shaken vigorously for $3 \mathrm{~min}$ in a sealed flask. Then the mixture was centrifuged at $26,000 \times \mathrm{g}$ for $5 \mathrm{~min}$ at $25{ }^{\circ} \mathrm{C}$. The upper layer was collected, transferred to a centrifuge tube and $12-\mathrm{mL}$ of distilled water was added, after which the mixture was centrifuged again for another $5 \mathrm{~min}$, followed by collecting the upper phase and evaporating to dryness at $35{ }^{\circ} \mathrm{C}$ under vacuum. The residue was dissolved in $1-\mathrm{mL}$ of hexane-1,2-dichloroethane $(1: 1, \mathrm{v} / \mathrm{v})$ and the solution was poured into a $\mathrm{NH}_{2}$ cartridge for purification. Initially, 5-mL of hexane was added to the cartridge to remove impurities such as paraffin oil, followed by adding 25-mL of hexane-1,2-dichloroethane-isopropanol (50:30:15, v/v/v) to elute cholesterol and COPs. The eluate was evaporated to dryness at $35{ }^{\circ} \mathrm{C}$ under vacuum, with the residue dissolved in hexane-isopropanol $(95: 5, \mathrm{v} / \mathrm{v})$ and filtered through a $0.2-\mu \mathrm{m}$ membrane filter for HPLC analysis.

\subsection{Extraction and Purification of Quercetin}

Each heated quercetin sample containing cholesterol was mixed with 7.5-mL of hexane-isopropanol $(3: 2, \mathrm{v} / \mathrm{v})$ in a flask, the mixture was then flushed with nitrogen gas and shaken vigorously for $3 \mathrm{~min}$, after which $3-\mathrm{mL}$ of distilled water was added and the mixture was shaken vigorously for another $3 \mathrm{~min}$. Then the solution was centrifuged at $26,000 \times \mathrm{g}$ for $5 \mathrm{~min}$ at $25^{\circ} \mathrm{C}$, followed by collecting the lower layer containing quercetin, pouring into a centrifuge tube, adding 3-mL of absolute ethanol, centrifuging again for $5 \mathrm{~min}$ and collecting the lower phase. Next, a $500-\mu \mathrm{L}$ of the lower phase was poured into a C18-E solid phase extraction cartridge, which was previously activated with 3-mL of methanol. Five $\mathrm{mL}$ of water-acetonitrile $(1: 1, \mathrm{v} / \mathrm{v})$ was added to elute quercetin, and the elute was filtered through a $0.2-\mu \mathrm{m}$ membrane filter for HPLC analysis.

\subsection{HPLC Analysis of Quercetin}

The heated sample containing quercetin was dissolved in $20-\mathrm{mL}$ of acetonitrile/phosphate buffer $(\mathrm{pH} 4)(55: 45, \mathrm{v} / \mathrm{v})$. Six concentrations of 1, 5, 10, 15, 20 and $25 \mathrm{mg} / \mathrm{L}$ of quercetin were each prepared in the same buffer solution. All the quercetin standard solutions were filtered through a $0.2-\mu \mathrm{m}$ 
membrane filter and a $20-\mu \mathrm{L}$ sample was injected into HPLC. A mobile phase of acetonitrilephosphoric acid buffer ( $\mathrm{pH} 4)(55: 45, \mathrm{v} / \mathrm{v})$ and a Vydac 201TP54 C18 column with flow rate at $1.5 \mathrm{~mL} / \mathrm{min}$ was used to separate and quantify quercetin at $460 \mathrm{~nm}$. The standard curve of quercetin was obtained by plotting concentration against peak area, and the regression equation and correlation coefficient $\left(\mathrm{r}^{2}\right)$ were calculated. A high recovery of $98 \%$ was obtained when quercetin standard was added and subjected to the same extraction and purification procedure. Triplicate analyses were conducted and the mean values were determined.

\subsection{TLC Analysis of COPs}

The Wurster dye was prepared as described by Smith and Hill [18]. One g of $N, N$-dimethyl-pphenylenediamine dihydrochloride was dissolved in $100 \mathrm{~mL}$ of $50 \%$ methanol solution, followed by shaking the mixture thoroughly, adding $1-\mathrm{mL}$ of glacial acetic acid, pouring the solution into a glass vial and storing at $-20{ }^{\circ} \mathrm{C}$ until use. For TLC analysis, the plate $(20 \times 20 \mathrm{~cm})$ precoated with silica gel with a thickness of $250 \mu \mathrm{m}$ was lined with a filter paper in a developing glass tank. A mobile phase of $200 \mathrm{~mL}$ of benzene-ethyl acetate $(60: 40, \mathrm{v} / \mathrm{v})$ was poured into the tank and allowed to equilibrate for $30 \mathrm{~min}$ for vapor saturation prior to development [26]. A micropipette was used to spot a $10-\mu \mathrm{L}$ volume of extract onto the glass plate, and the chromatogram was developed for a distance of $18 \mathrm{~cm}$ at $25{ }^{\circ} \mathrm{C}$, after which the plate was dried in an oven at $110{ }^{\circ} \mathrm{C}$ for $10 \mathrm{~min}$, followed by spraying with $50 \%$ $\mathrm{H}_{2} \mathrm{SO}_{4}$. The color development of COPs under UV radiation at $254 \mathrm{~nm}$ was observed and recorded. In addition, the red spot was further subjected to HPLC analysis.

\subsection{HPLC Analysis of COPs}

Two LiChrospher $100 \mathrm{CN}$ columns connected in series and an isocratic solvent system of hexaneisopropanol $(95: 5, \mathrm{v} / \mathrm{v})$ with flow rate at $1.0 \mathrm{~mL} / \mathrm{min}$ were used to separate cholesterol and various COPs with RI detection. Identification was accomplished by comparing retention times of unknown peaks with authentic standards and cochromatography with added standards. An external calibration method was employed for quantification of various COPs. Seven concentrations of cholesterol (0.5, $1.0,2.5,5,10,25$ and $50 \mathrm{mg} / \mathrm{mL})$ and COPs $(50,100,200,500,1000,2500$ and $5000 \mu \mathrm{g} / \mathrm{mL})$ were each prepared and the standard curve was obtained by plotting concentration against area after injecting into HPLC. The regression equations and correlation coefficients $\left(\mathrm{r}^{2}\right)$ were obtained by using a Borwin software system. Recovery was carried out by adding a fixed concentration of cholesterol and various COPs standards to samples for extraction and HPLC analysis, and a high recovery ranging from $97-100 \%$ was attained.

\subsection{Kinetic Analysis of COPs and Quercetin}

The concentration changes of quercetin during heating in the presence of nitrogen, oxygen or cholesterol were statistically analyzed using a non-linear regression procedure of SAS [24]. Also, the formation of COPs and degradation of cholesterol were analyzed statistically. The rate constant of each reaction was determined based on the least square method, i.e., the Marquardt iterative procedure, until the convergence of all the parameters was best fitted. The precision of the parameters for each 
kinetic equation was also assessed. Analysis of variance and comparison of the residual amounts of cholesterol at various heating time intervals were carried out by using the SAS system [24]. After a preliminary F test, the differences among the residual cholesterol were analyzed by Duncan's multiple range test $(\mathrm{p}<0.05)$.

\section{Conclusions}

In conclusion, the major reaction pathways during heating of quercetin with and without cholesterol at $150{ }^{\circ} \mathrm{C}$ included cholesterol peroxidation and epoxidation, as well as thermal degradation, oxidative degradation and free radical chain reaction of quercetin. The correlation coefficients $\left(r^{2}\right)$ for all the reactions ranged from 0.82-0.99 based on non-linear regression analysis for cholesterol when heated with quercetin. The reactions for 7-OOH and 5,6-epoxide formation fitted the second-order, while all the reaction for quercetin degradation and free radical reaction fitted the first-order. The kinetic model developed in this study may be applied to predict the concentration changes of quercetin degradation in the presence and absence of cholesterol during heating at $150{ }^{\circ} \mathrm{C}$.

\section{References}

1. Hertog, M.G.L.; Hollman, P.C.H.; Katan, M.B. Content of potentially anticarcinogenic flavonoids of 28 vegetables and 9 fruits commonly in the Netherlands. J. Agric. Food Chem. 1992, 40, 2379-2383.

2. Miean, K.H.; Mohamed, S. Flavonoids (myricetin, quercetin, kaempferol, luteolin, and apigenin) content of edible tropical plants. J. Agric. Food Chem. 2001, 49, 3106-3112.

3. Hopia, A.; Heinonen, M. Antioxidant activity of flavonol aglycones and their glycosides in methyl linoleate. J. Am. Oil Chem. Soc. 1999, 76, 139-144.

4. Das, N.P.; Pereira, T.A. Effects of flavonoids on thermal autoxidation of palm oil: Structureactivity relationships. J. Am. Oil Chem. Soc. 1990, 67, 255-258.

5. Makris, D.P.; Rossiter, J.T. Quercetin and rutin (quercetin 3-O-rhamnosylglucoside) thermal degradation in aqueous media under alkaline condition. In Functional Foods-Claims and Evidence; Buttriss, J., Saltmarsh, M., Eds.; Royal Society of Chemistry Press: London, UK, 2000; pp. 216-238.

6. Makris, D.P.; Rossiter, J.T. Heat-induced, metal-catalyzed oxidative degradation of quercetin and rutin (quercetin 3-o-rhamnosylglucoside) in aqueous model systems. J. Agric. Food Chem. 2000, 48, 3830-3838.

7. Nieto, S.; Garrido, A.; Sanhueza, J.; Loyola, L.A.; Morales, G.; Leighton, F.; Valenzuela, A. Flavonoids as stabilizers of fish oil: An alternative to synthetic antioxidants. J. Am. Oil Chem. Soc. 1993, 70, 773-778.

8. Pekkarinen, S.S.; Heinonen, I.M.; Hopia, A.I. Flavonoids quercetin, myricetin, kaemferol and $(+)$-catechin as antioxidants in methyl linoleate. J. Sci. Food Agric. 2000, 79, 499-506.

9. Xu, G.; Guan, L.; Sun, J.; Chen, Z.Y. Oxidation of cholesterol and $\beta$-sitosterol and prevention by natural antioxidants. J. Agric. Food Chem. 2009, 57, 9284-9292.

10. Maerker, G. Cholesterol autoxidation-current status. J. Am. Oil Chem. Soc. 1987, 64, 388-392. 
11. Paniangvait, P.; King, A.J.; Jones, A.D.; German, B.G. Cholesterol oxides in foods of animal origin. J. Food Sci. 1995, 60, 1159-1174.

12. Chien, J.T.; Wang, H.C.; Chen, B.H. Kinetic model of the cholesterol oxidation during heating. J. Agric. Food Chem. 1998, 46, 2572-2577.

13. Chien, J.T.; Huang, D.Y.; Chen, B.H. Kinetic study of the cholesterol oxidation as inhibited by stearylamine during heating. J. Agric. Food Chem. 2004, 52, 7132-7138.

14. Xu, G.; Sun, J.; Liang, Y.; Yang, C.; Chen, Z.Y. Interaction of fatty acids with oxidation of cholesterol and $\beta$-sitosterol. Food Chem. 2010, in press, doi:10.1016/j.foodchem.2010.06.003.

15. Mahfaouz, M.M.; Kummerow, F.A. Cholesterol-rich diets have different effects on lipid peroxidation, cholesterol oxides, and antioxidant enzymes in rats and rabbits. J. Nutr. Biochem. 2000, 11, 293-302.

16. Leonarduzzi, G.; Sottero, B.; Poli, G. Oxidized products of cholesterol: Dietary and metabolic origin and proatherosclerotic effects (review). J. Nutr. Biochem. 2002, 13, 700-710.

17. Chien, J.T.; Hsu, D.J.; Chen, B.H. Kinetic model for studying the effect of quercetin on cholesterol oxidation during heating. J. Agric. Food Chem. 2006, 54, 1486-1492.

18. Smith, L.L. Cholesterol autoxidation 1981-1986. Chem. Phys. Lipids 1987, 44, 87-125.

19. Pryor, W.A.; Cornicelli, J.A.; Devall, L.J.; Tait, B.; Trivedi, B.K.; Witiak, D.T.; Wu, M.A. Rapid screening test to determine the antioxidant potencies of natural and synthetic antioxidants. J. Org. Chem. 1993, 58, 3521-3532.

20. Foti, M.; Ruberto, G. Kinetic solvent effects on phenolic antioxidants determined by spectrophotometric measurements. J. Agric. Food Chem. 2001, 49, 342-348.

21. Foti, M.; Piattelli, M.; Baratta, M.T.; Ruberto, G. Flavonoids, coumarins, and cinnamic acids as antioxidants in a micellar system. Structure-activity relationship. J. Agric. Food Chem. 1996, 44, 497-501.

22. Ozilgen, S.; Ozilgen, M. Kinetic model of lipid oxidation in foods. J. Food Sci. 1990, 55, 498-536.

23. Smith, L.L.; Hill, F.L. Detection of sterol hydroperoxides on thin layer chromatoplates by means of the wurster dyes. J. Chromatogr. 1972, 66, 101-109.

24. SAS. SAS Procedures and SAS/Graph User's Guide, Version 9.1.3 Foundation. Software Release 9.1 (TS1M3 DSCS3054) of the SAS System for Microsoft windows XP Professional. SAS Institute, Inc.: Cary, NC, USA, 1999.

25. Nourooz-Zadeh, J. Determination of autoxidation products from free or total cholesterol: A new multistep enrichment methodology including the enzymatic release of esterified cholesterol. $J$. Agric. Food Chem. 1990, 38, 1667-1673.

26. Maerker, G.; Bunick, F.J. Cholesterol oxides: Isolation and determination of some cholesterol oxidation products. J. Am. Oil Chem. Soc. 1986, 63, 767-771.

(C) 2010 by the authors; licensee MDPI, Basel, Switzerland. This article is an Open Access article distributed under the terms and conditions of the Creative Commons Attribution license (http://creativecommons.org/licenses/by/3.0/). 